\title{
The Effect Of Health Education On Knowledge About Anemia In Pregnant Mother
}

\author{
Fitriani $^{1}$, A.Nurlaela Amin ${ }^{2}$, Uswatun Khasanah ${ }^{3}$ \\ ${ }^{1}$ Department of Nursing, Stikes Panrita Husada Bulukumba, Indonesia \\ ${ }^{2}$ Department of Nursing, Stikes Panrita Husada Bulukumba, Indonesia \\ ${ }^{3}$ Nursing Student, Stikes Panrita Husada Bulukumba, Indonesia
}

Corresponding author: Fitriani

Email: fitrianiviviambo@gmail.com

\begin{abstract}
Anemia in pregnancy is one of the national problems because it reflects the value of the socioeconomic welfare of the community and its influence is very large on the quality of human resources. The prevalence of anemia in the world is very high, especially in developing countries including in Indonesia, anemia is still four of the nutritional problems that have not been resolved, even becoming the main cause of maternal and neonatal mortality. As many as 40 percents of deaths in pregnant women are caused by anemia. Therefore, anemia requires serious attention from all parties involved in health care. The purpose of this study is to know the effect of health education on the level of knowledge about anemia in pregnant women in the working area of the Borong Rappoa Puskesmas. This type of research is a quantitative study with a pre-experimental research design through the onegroup pretest-posttest design method. The sampling technique uses the non-probability sampling technique that is consecutive so that it gets 44 respondents as respondents. The results of the study used the Wilcoxon test with a significance value of $<0.05$. The results obtained before being given health education, most pregnant women lack knowledge as many as 40 people (90.9\%) of respondents, enough as many as 3 people $(6.8 \%)$ of respondents, either there is 1 person $(2.3 \%)$ of respondents and after giving health education, most of the pregnant women have good knowledge as many as 39 people $(88.6 \%)$ of respondents, have enough knowledge of 5 people $(11.4 \%)$ of respondents, and lack of knowledge of $0(0 \%)$, so $\mathrm{p}$ values $=0,000<0,05$ which means there are differences in the proportions before and after the provision of health education about anemia in pregnancy.
\end{abstract}

Keywords: Anemia, Health Education, Knowledge 


\section{PENDAHULUAN}

Anemia pada kehamilan merupakan salah satu masalah nasional karena mencerminkan nilai kesejahteraan sosial ekonomi masyarakat dan pengaruhnya sangat besar terhadap kualitas sumber daya manusia. Anemia pada ibu hamil disebut "Potensial danger to mother and child" (potensial membahayakan ibu dan anak). Oleh karena itulah anemia memerlukan perhatian serius dari semua pihak yang terkait dalam pelayanan kesehatan (Nurhidayati, 2013). Anemia pada kehamilan adalah kondisi ibu dengan kadar haemoglobin ( $\mathrm{Hb})$ dibawah 11 gram \% pada trimester satu dan tiga atau kadar $\mathrm{Hb}$ kurang dari 10,5 gram \% pada trimester dua. Ibu hamil yang anemia ( kekurangan zat bezi) mempunyai resiko yang lebih besar untuk melahirkan bayi dengan berat badan lahir rendah (BBLR), abortus, terjadi kematian intra uteri, persalinan prematuritas tinggi, cacat bawaan, intelegensi rendah. Untuk ibu mudah terjadi perdarahan antepartum, infeksi, ketuban pecah dini dan gangguan HIS (Manuaba dalam (Tuyu, 2013). Anemia menjadi penyebab utama terjadinya mortalitas maternal dan neonatal di negara-negara berkembang, termasuk Indonesia, yang bisa menyebabkan 2,5-3,4 juta kematian penduduk di negara berkembang, termasuk Indonesia. Sejumlah 40 persen kematian pada ibu hamil berhubungan dengan anemia (Aditianti, Yurista and Diana, 2015).

Menurut World Health Organization (WHO) tahun 2018, kejadian anemia berkisar hingga 48,1\% dari semua wanita yang tinggal di negara berkembang, termasuk Indonesia. Anemia selama kehamilan merupakan penyebab utama morbiditas dan mortalitas wanita hamil di negara berkembang dan memiliki konsekuensi ibu dan janin. Diperkirakan anemia menyebabkan lebih dari 115,000 kematian ibu dan 592,000 kematian perinatal secara global per tahun (Shridevi, 2018). Di Indonesia, hasil Riset Kesehatan Dasar (Riskesdas) tahun 2018 menunjukkan prevalensi anemia pada ibu hamil masih sangat tinggi, yakni 48,9 persen (Kemenkes 2018), yang menunjukkan bahwa prevalensi anemia pada ibu hamil mengalami peningkatan dari hasil Riskesdas 2013, yakni 37,1 persen. Di negara berkembang, satu dari dua ibu hamil diperkirakan anemia. Anemia menjadi masalah kesehatan berat (severe public health problem), jika prevalensinya lebih dari 40 persen dalam suatu wilayah.

Berdasarkan data dari profil kesehatan provinsi Sulawesi Selatan tahun 2017, ditemukan jumlah ibu hamil yang mendapatkan tablet tambah darah (TTD) sebanyak 47,7 persen. Untuk kabupaten Bulukumba, kasus anemia pada ibu hamil di tahun 2018 tercatat sebanyak 1.654 ibu hamil yang mengalami anemia berdasarkan laporan dari 20 puskesmas yang berada di kabupaten Bulukumba. Dan untuk Puskesmas Borong Rappoa sendiri pada tahun 2018 tercatat sebanyak 124 ibu hamil dengan anemia dari 244 jumlah ibu hamil secara keseluruhan. 
Berdasarkan wawancara sederhana yang dilakukan oleh peneliti serta pembagian kuesioner pada bulan Maret 2019 terkait tentang anemia pada beberapa ibu hamil tanpa memperhatikan kriteria yang ada, dapat memberikan gambaran bahwa tingkat pengetahuan ibu hamil terkait anemia pada kehamilan di wilayah kerja Puskesmas Borong Rappoa memang masih kurang. Ini dibuktikan dari jawaban mereka pada saat dilakukan wawancara serta jawaban dari kuesioner yang telah dibagikan rata-rata mendapatkan angka $<56 \%$.

Faktor yang menyebabkan masih tingginya kejadian anemia pada ibu hamil salah satunya dipengaruhi oleh tingkat pengetahuan yang masih kurang tentang anemia termasuk upaya pencegahan dan dampaknya. Tingkat pengetahuan ibu hamil yang rendah akan mempengaruhi bagaimana ibu hamil menjaga kehamilannya. Pengetahuan yang kurang memiliki risiko 1,45 kali lebih besar untuk menderita anemia dalam kehamilannya dibandingkan dengan ibu hamil yang berpengetahuan baik (Iswanto, Ichsan and Ermawati, 2012). Pengetahuan merupakan salah satu faktor yang menstimulasi atau merangsang terhadap terwujudnya sebuah perilaku kesehatan. Apabila ibu hamil mengetahui dan memahami akibat anemia dan cara mencegah anemia maka akan mempunyai perilaku kesehatan yang baik dengan harapan dapat terhindar dari berbagai akibat atau risiko dari terjadinya anemia kehamilan. Perilaku kesehatan yang demikian berpengaruh terhadap penurunan kejadian anemia pada ibu hamil (Purbadewi and Ulvie, 2013).

Tentu hal ini akan lebih gampang terealisasi apabila ibu hamil telah memahami konsepnya. Konsep yang baik akan diperoleh salah satunya dengan cara memberikan penyuluhan/pendidikan kesehatan. Dengan memberikan pendidikan kesehatan yang baik akan mempermudah ibu hamil untuk mengadopsi pengetahuan tentang kesehatannya sehingga mampu dalam upaya menangani masalah gizi dan kesehatan keluarga (Nurhidayati, 2013). Adapun dampak anemia pada kehamilan jika tidak segera diatasi menurut Dr.Demsa Simbolon, SKM.,M.Gizi antara lain : bagi Ibu hamil berisiko dan komplikasi seperti anemia, perdarahan, berat badan ibu tidak bertambah secara normal dan bisa terkena penyakit infeksi bahkan meningkatkan resiko kematian ibu. Adapun dampak bagi proses persalinan yakni kondisi anemia pada kehamilan berisiko menurunkan kekuatan otot yang membantu proses persalinan sehingga berisiko terjadinya persalinan yang sulit dan lama, persalinan premature/sebelum waktunya, perdarahan post partum, serta persalinan dengan tindakan operasi cesar cenderung meningkat.

Sementara dampak bagi janin dan anak antara lain, bagi janin dapat terjadi gangguan pertumbuhan janin dan dapat menimbulkan keguguran, abortus, bayi lahir mati, kematian 
neonatal, cacat bawaan, asfiksia intra partum, lahir dengan berat badan rendah (BBLR). Dan dampak bagi anak bisa mengganggu tumbuh kembang anak, yaitu pertumbuhan fisik (stunting), otak dan metabolisme yang menyebabkan penyakit tidak menular diusia dewasa (Simbolon, Jumiyati and Rahmadi, 2018).

Berdasarkan penelitian yang telah dilakukan oleh Rismintari tahun 2015 pada semua ibu hamil yang ada di Desa Palbapang, Kabupaten Bantul yang menjelaskan bahwa terdapat perbedaan yang sangat signifikan antara tingkat pengetahuan ibu hamil tentang anemia sebelum dan sesudah diberikan pendidikan kesehatan (Rismintari, 2015). Penelitian yang sama juga dilakukan oleh Siti Santy Sianipar, dkk. di UPT. Puskesmas Bukit Hindu Palangkaraya pada tahun 2016, dapat disimpulkan bahwa ada perbedaan tingkat pengetahuan ibu hamil dalam pencegahan anemia sebelum dan sesudah diberikan pendidikan kesehatan. Ini membuktikan bahwa pendidikan kesehatan mempunyai pengaruh yang cukup besar terhadap tingkat pengetahuan ibu hamil dalam pencegahan anemia (Sianipar, Aziz and Prilia, 2016).

Dalam penelitian yang dilakukan oleh Elsy Noverstiti tahun 2012 di Puskesmas Air Dingin kota Padang dapat disimpulkan bahwa tingkat pengetahuan merupakan salah satu faktor yang mempengaruhi kejadian anemia pada ibu hamil (Noverstiti, 2012). Berdasarkan hal tersebut yang dikemukakan di atas yang berpedoman pada penelitian terdahulu yang telah dilakukan bahwa anemia pada kehamilan dapat memberikan dampak yang buruk bagi ibu dan bayi, bahkan bisa menjadi penyebab meningkatnya angka kematian ibu (AKI). Maka dapat ditarik kesimpulan bahwa pemberian pendidikan kesehatan memang penting dalam upaya menunjang tingkat pengetahuan ibu hamil mengenai pencegahan anemia pada kehamilan. Tingginya angka kejadian ibu hamil dengan anemia, baik di Indonesia maupun di Puskesmas Borong Rappoa yang mempunyai ibu hamil dengan anemia yang cukup banyak dibanding beberapa puskesmas lain yang ada di kabupaten Bulukumba, yakni terdapat 124 orang ibu hamil dengan anemia dari 244 orang jumlah ibu hamil pada tahun 2018. Faktor tersebut salah satunya dipengaruhi oleh kurangnya pengetahuan ibu hamil tentang anemia termasuk dalam melakukan kunjungan antenatal care (ANC). Sesuai yang dikatakan oleh kepala ruang KIA puskesmas Borong Rappoa, dari sekian banyak ibu hamil setiap tahun, hanya sekitar \pm 50 orang ibu hamil yang rutin melakukan pemeriksaan antenatal care sampai melahirkan. 


\section{METODE PENELITIAN}

\section{Desain penelitian}

Jenis penelitian ini adalah penelitian kuantitatif dengan rancangan penelitian pre eksperimental dimana penelitian ini masih terdapat variabel luar yang ikut berpengaruh terhadap terbentuknya variabel dependen. Jadi hasil eksperimen yang merupakan variabel dependen itu bukan semata-mata dipengaruhi oleh variabel independen (Sugiyono, 2018).

Penelitian ini menggunakan metode one group pretest posttest design yaitu peneliti mengambil satu sampel kemudian sebelum diberikan perlakuan, sampel diberikan pretest terlebih dahulu. Setelah diberi perlakuan, sampel kembali diberikan posttest. Langkah terakhir hasil pretest dan posttest dibandingkan (Kristanto, 2018).

\section{Populasi dan sampel}

Populasi adalah wilayah generalisasi yang terdiri atas : obyek/subyek yang mempunyai kualitas dan karakteristik tertentu yang ditetapkan oleh peneliti untuk dipelajari dan kemudian ditarik kesimpulannya (Sugiyono, 2018). Populasi dalam penelitian ini adalah keseluruhan ibu hamil yang berada dalam wilayah kerja Puskesmas Borong Rappoa Kecamatan Kindang Kabupaten Bulukumba sebanyak 180 orang pada periode bulan Januari - Juni 2019. Sampel penelitian adalah sebagian dari keseluruhan objek yang diteliti dan dianggap mewakili seluruh populasi (Setiadi, 2013). Sampel dalam penelitian ini sebanyak 44 orang ibu hamil yang berada di Puskesmas Borong Rappoa. Teknik pengambilan sampel dalam penelitian ini dengan menggunakan teknik Non Probability Sampling yaitu teknik pengambilan sampel yang tidak memberi peluang/kesempatan sama bagi setiap unsur atau anggota populasi untuk dipilih menjadi sampel (Sugiyono, 2018). Dalam penentuan sampel, peneliti menggunakan teknik consecutive sampling yaitu semua subjek yang datang dan memenuhi kriteria penelitian sampai jumlah subjek yang dibutuhkan terpenuhi (Oktavia, 2015).

\section{Instrumen pengumpulan data}

Pada tingkat pengetahuan (variabel dependen) peneliti menggunakan instrumen penelitian berbentuk kuesioner. kuesioner untuk menggali pengetahuan tentang anemia pada kehamilan disusun dengan model multiple choice (pilihan ganda) sebanyak 20 nomor dengan menggunakan skala Guttman. Apabila responden menjawab pertanyaan dengan benar diberi skor 1 dan apabila salah diberi skor 0. Sedangkan pada pendidikan kesehatan (variabel independen) peneliti menggunakan metode ceramah selama \pm 90 menit dengan menggunakan bahasa Indonesia sederhana (yang mudah dipahami responden) serta menggunakan media leaflet yang dibagikan pada responden. 


\section{Analisa data}

Analisa bivariat adalah analisa yang dilakukan lebih dari dua variabel. Analisa bivariat pada penelitian ini adalah untuk menganalisa pengaruh pendidikan kesehatan terhadap tingkat pengetahuan dalam upaya pencegahan anemia pada ibu hamil (Sujarweni, 2014). Variabel ini dianalisa dengan menggunakan uji Marginal Homogenity dengan tingkat kemaknaan $\alpha \leq 0,05$ yang dilakukan dengan bantuan komputer SPSS.

\section{HASIL}

Berdasarkan tabel 1 diatas menunjukkan bahwa responden dengan pendidikan terbanyak adalah pendidikan rendah dengan jumlah 27 orang $(61,4 \%)$ responden dan pendidikan tinggi dengan jumlah 17 orang $(38,6 \%)$ responden. Dari hasil di atas, peneliti berasumsi bahwa tingkat pendidikan sangat mempengaruhi bagaimana seseorang untuk bertindak dan mencari penyebab serta solusi dalam hidupnya. Orang yang berpendidikan tinggi akan bertindak lebih rasional. Demikian halnya dengan ibu yang berpendidikan tinggi akan memeriksakan kehamilannya secara teratur demi menjaga keadaan kesehatan dirinya dan anak dalam kandungannya.

\section{Tabel 1 Karasteristik Distribusi Responden Berdasarkan Pendidikan Di Wilayah Kerja Puskesmas Borong Rappoa}

\begin{tabular}{ccc}
\hline Pendidikan & Frekuensi (n) & Percent (\%) \\
\hline Tinggi (SMA, PT) & 17 & 38,6 \\
Rendah (SD, SMP) & 27 & 61,4 \\
\hline Total & $\mathbf{4 4}$ & $\mathbf{1 0 0}$ \\
\hline
\end{tabular}

Berdasarkan tabel 2 di atas menunjukkan bahwa responden yang terbanyak dalam penelitian ini adalah usia 17-25 sebanyak 21 orang $(47,7 \%)$ responden dan yang terendah adalah usia 36-45 sebanyak 4 orang $(9,1 \%)$ responden. Dari hasil data di atas, peneliti berasumsi bahwa semakin cukup usia atau semakin dewasa seseorang, tingkat kematangan dan kekuatan seseorang akan lebih matang dalam berpikir, bekerja dan bertindak.

\section{Tabel 2. Karasteristik Distribusi Responden Berdasarkan Usia Di Wilayah Kerja Puskesmas Borong Rappoa}

\begin{tabular}{ccc}
\hline Usia & Frekuensi (n) & Percent (\%) \\
\hline Remaja akhir (16-25 tahun) & 21 & 47,7 \\
Dewasa awal (26-35 tahun) & 19 & 43,2 \\
Dewasa akhir (36-45 tahun) & 4 & 9,1 \\
\hline Total & $\mathbf{4 4}$ & $\mathbf{1 0 0}$ \\
\hline
\end{tabular}

Berdasarkan data dari tabel 3 ditemukan status pekerjaan responden yang terbanyak adalah tidak bekerja sebanyak 40 orang $(90,9 \%)$ responden dan status pekerjaan responden yang terendah adalah bekerja sebanyak 4 orang $(9,1 \%)$ responden. Dari hasil tabel di atas, 
peneliti berasumsi bahwa pekerjaan, pendidikan, dan pengetahuan merupakan satu paket yang tak dapat dipisahkan. Dapat dilihat dari tabel bahwa responden yang mempunyai pekerjaan tetap berasal dari pendidikan tinggi, sementara seseorang yang mempunyai pendidikan secara tidak langsung akan dengan mudah membawa perubahannya ke arah yang lebih baik.

Tabel 3. Karasteristik Distribusi Responden Berdasarkan Pekerjaan Di Wilayah Kerja Puskesmas Borong Rappoa

\begin{tabular}{ccc|}
\hline Pekerjaan & Frekuensi (n) & Percent (\%) \\
\hline Bekerja (PNS, Tenaga honorer) & 4 & 9,1 \\
Tidak bekerja (IRT) & 40 & 90,9 \\
\hline Total & $\mathbf{4 4}$ & $\mathbf{1 0 0}$ \\
\hline
\end{tabular}

Berdasarkan data dari tabel 4 terlihat bahwa usia kehamilan responden yang terbanyak yaitu di trimester 3 sebanyak 22 orang $(50,0 \%)$ dan yang terendah yaitu trimester 1 sebanyak 6 orang $(13,6 \%)$. Dari tabel di atas, peneliti berasumsi bahwa semakin tua usia kehamilan pada seseorang, semakin tinggi pula kebutuhan akan produksi sel darah merah dalam tubuhnya. Ini sejalan dengan teori yang mengatakan bahwa sel darah merah (khususnya zat besi) yang ada pada tubuh seseorang sebelum hamil masih dapat mencukupi kebutuhan akan hal tersebut diawal kehamilan (trimeseter I), lain halnya pada trimeseter II ataupun III.

\section{Tabel 4.Karasteristik Distribusi Responden Berdasarkan Usia Kehamilan Di Wilayah Kerja Puskesmas Borong Rappoa}

\begin{tabular}{ccc}
\hline Usia Kehamilan & Frekuensi (n) & Percent (\%) \\
\hline Trimester 1 (0-12 minggu) & 6 & 13,6 \\
Trimester 2 (13-27 minggu) & 16 & 36,4 \\
Trimester 3 (28-40 minggu) & 22 & 50,0 \\
\hline Total & $\mathbf{4 4}$ & $\mathbf{1 0 0}$ \\
\hline
\end{tabular}

Berdasarkan data dari tabel 5 terlihat bahwa riwayat kehamilan responden sebagian besar didominasi oleh riwayat kehamilan $\leq 1$ kali sebanyak 25 orang $(56,8 \%)$, sementara kehamilan pertama sebanyak 19 orang $(43,2 \%)$. Peneliti berasumsi bahwa tingkat pengetahuan ibu hamil, khususnya terkait tentang anemia, tidak ada kaitannya dengan pengalaman ibu tentang kehamilan. Ini dibuktikan oleh data yang menunjukkan bahwa dari 44 orang ibu hamil dengan anemia, sebagian besar bahkan didominasi oleh ibu hamil dengan riwayat kehamilan $>1$ kali

Tabel 5. Karasteristik Distribusi Responden Berdasarkan Riwayat Kehamilan Di Wilayah Kerja Puskesmas Borong Rappoa

\begin{tabular}{lcc}
\multicolumn{1}{c}{ Riwayat Kehamilan } & Frekuensi (n) & Percent (\%) \\
\hline Kehamilan 1 kali (Pertama) & 19 & 43,2 \\
Kehamilan > 1 kali & 25 & 56,8 \\
\hline \multicolumn{1}{c}{ Total } & $\mathbf{4 4}$ & $\mathbf{1 0 0}$ \\
\hline
\end{tabular}


Dari hasil tabel 6. menunjukkan bahwa dari 44 responden, sebagian besar responden dengan pengetahuan kurang sebanyak 40 orang $(90,9 \%)$ responden, pengetahuan cukup 3 orang $(6,8 \%)$ responden dan pengetahuan baik 1 orang $(2,3 \%)$ responden.

Tabel 6. Distribusi Pengetahuan Ibu Hamil Tentang Anemia Sebelum Diberikan Pendidikan Kesehatan Di Wilayah Kerja Puskesmas Borong Rappoa

\begin{tabular}{lcc}
\multicolumn{1}{c}{ Pengetahuan } & Frekuensi (n) & Percent (\%) \\
\hline Baik $(76-80 \%)$ & 1 & 2,3 \\
Cukup $(56-75 \%)$ & 3 & 6,8 \\
Kurang $(<56)$ & 40 & 90,9 \\
\hline \multicolumn{1}{c}{ Total } & $\mathbf{4 4}$ & $\mathbf{1 0 0}$ \\
\hline
\end{tabular}

Berdasarkan data pada tabel 7 menunjukkan bahwa dari 44 responden, yang paling banyak dengan kategori pengetahuan baik sebanyak 39 orang $(88,6 \%)$ responden, kategori cukup 5 orang $(11,4 \%)$ dan kategori kurang $0(0 \%)$.

Tabel 7. Distribusi Pengetahuan Ibu Hamil Tentang Anemia Setelah Diberikan Pendidikan Kesehatan Di Wilayah Kerja Puskesmas Borong Rappoa

\begin{tabular}{ccc}
\hline Pengetahuan & Frekuensi (n) & Percent (\%) \\
\hline Baik & 39 & 88,6 \\
Cukup & 5 & 11,4 \\
Kurang & 0 & 0 \\
\hline Total & $\mathbf{4 4}$ & $\mathbf{1 0 0}$ \\
\hline
\end{tabular}

Berdasarkan tabel 8 di atas dari total 44 responden menunjukkan bahwa nilai pre-test pengetahuan dan post-test pengetahuan didapatkan nilai p 0,000 atau $<0,05$, maka Ho ditolak artinya ada perbedaan proporsi sebelum dan sesudah diberikan pendidikan kesehatan.

Tabel 8. Pengaruh Pendidikan Kesehatan Terhadap Tingkat Pengetahuan Tentang Anemia Pada Ibu Hamil Di Wilayah Kerja Puskesmas Borong Rappoa

\begin{tabular}{|c|c|c|c|c|c|c|c|c|c|}
\hline \multirow{3}{*}{$\begin{array}{c}\text { Pendidikan } \\
\text { Kesehatan }\end{array}$} & \multicolumn{8}{|c|}{ Tingkat pengetahuan } & \multirow{3}{*}{ Nilai $p$} \\
\hline & \multicolumn{2}{|c|}{ Baik } & \multicolumn{2}{|c|}{ Cukup } & \multicolumn{2}{|c|}{ Kurang } & \multicolumn{2}{|c|}{ Jumlah } & \\
\hline & $\mathbf{F}$ & $\%$ & $\mathbf{f}$ & $\%$ & $\mathbf{f}$ & $\%$ & $\mathbf{F}$ & $\%$ & \\
\hline Pre-test & 1 & 2.3 & 3 & 6,8 & 40 & 90,9 & 44 & 100 & 0,000 \\
\hline Post-test & 39 & 88,6 & 5 & 11,4 & 0 & 0 & 44 & 100 & \\
\hline
\end{tabular}

\section{PEMBAHASAN}

Hasil penelitian sebelum diberikan pendidikan kesehatan (pretest) menunjukkan bahwa dari 44 orang responden, sebagian besar responden dengan pengetahuan kurang sebanyak 40 orang $(90,9 \%)$ responden, pengetahuan cukup sebanyak 3 orang $(6,8 \%)$ responden, dan pengetahuan baik sebanyak 1 orang $(2,3 \%)$ responden. Pendidikan mempengaruhi proses belajar, makin tinggi pendidikan seseorang, makin mudah orang tersebut untuk menerima 
informasi. Dengan pendidikan tinggi, maka seseorang akan cenderung untuk mendapatkan informasi baik dari orang lain maupun dari media massa. Semakin banyak informasi yang masuk, semakin banyak pula pengetahuan yang didapat tentang kesehatan. Pengetahuan sangat erat kaitannya dengan pendidikan seseorang. Dimana seseorang dengan pendidikan tinggi, maka orang tersebut akan semakin luas pula pengetahuannya.

Pengetahuan merupakan salah satu faktor yang menstimulasi atau merangsang terhadap terwujudnya sebuah perilaku kesehatan. Apabila ibu hamil mengetahui dan memahami konsepnya, maka akan mempunyai perilaku kesehatan yang baik. Pengetahuan ibu hamil dapat dipengaruhi oleh beberapa faktor diantaranya pendidikan, pekerjaan, umur, lingkungan dan sosial budaya (Purbadewi \& Ulvie, 2013). Hasil penelitian ini sejalan dengan penelitian yang dilakukan oleh Siti Santy Sianipar, dkk. dengan judul "Pengaruh Pendidikan Kesehatan Tentang Anemia Pada kehamilan Terhadap Pengetahuan Ibu Hamil Di UPT Puskesmas Bukit Hindu Palangka Raya Tahun 2016" menunjukkan bahwa sebelum diberikan pendidikan kesehatan dari 30 responden, 23 responden (77\%) berpengetahuan kurang, 7 responden (29\%) berpengetahuan cukup, dan 0 responden $(0 \%)$ berpengetahuan baik. Siti Santy Sianipar, dkk. berasumsi bahwa media yang menunjang dan strategi yang tepat dapat memperkaya pengetahuan ibu hamil tentang anemia pada kehamilan seperti media flipchart dan metode diskusi. Disamping dapat dilakukan guna meningkatkan pengetahuan ibu, hal itu juga dapat dilakukan sebagai salah satu upaya untuk meningkatkan pengetahuan pada kehamilan.

Penelitian yang sejalan juga dilakukan oleh Ana Mariza, dengan judul "Hubungan Pendidikan Dan Sosial Ekonomi Dengan Kejadian Anemia Pada Ibu Hamil di BPS T Yohan Way Halim Bandar Lampung Tahun 2015" dapat disimpulkan bahwa pendidikan erat dengan kemampuan menerima informasi yang berkaitan dengan kesehatan. Semakin tinggi tingkat pendidikan (lama sekolah) seseorang, semakin mudah baginya menerima hidup sehat secara mandiri, kreatif, dan berkesinambungan serta makin tinggi pula kesadarannya untuk mendapatkan gizi yang baik sehingga tidak menimbulkan anemia pada kehamilan dibandingkan seseorang dengan pendidikan rendah.

Dari hasil analisis peneliti sebelum diberikan pendidikan kesehatan sebagian besar responden memiliki pengetahuan kurang sebanyak 40 orang $(90,9 \%)$ responden, dikarenakan responden belum pernah terpapar informasi terkait tentang anemia. Ini dibuktikan dari pernyataan langsung dari ibu hamil pada saat dilakukan wawancara sederhana oleh peneliti sebelum diberikan pendidikan kesehatan, mereka mengaku tidak tahu dan tidak pernah mendengar apa itu anemia, apa dampaknya, dan bagaimana cara mencegahnya. Dapat dilihat 
dari jawaban pada kuesioner yang telah dibagikan pada responden sebelum diberikan penyuluhan, bahwa kebanyakan yang menjawab salah pada point yang terkait tentang definisi anemia dan klasifikasinya. Hal ini juga dapat terlihat dari karakteristik responden yang memberikan gambaran bahwa ibu hamil yang berada di wilayah kerja Puskesmas Borong Rappoa lebih banyak dengan pendidikan rendah yakni sebanyak $61,4 \%$ orang ibu hamil yang menderita anemia. Disamping itu, ibu hamil yang berada di lingkup kerja Puskesmas Borong Rappoa sangat sulit untuk dikumpulkan ketika akan diberikan penyuluhan-penyuluhan kesehatan dikarenakan budaya dan pola pikir ibu hamil yang cenderung lebih memandang bahwa materi jauh lebih penting dibandingkan sebuah pengetahuan.

Sebagian besar tingkat pengetahuan setelah diberikan pendidikan kesehatan yaitu memiliki tingkat pengetahuan baik sebesar 39 orang $(88,6 \%)$ responden dari sebelumnya 1 orang $(2,3 \%)$ responden yang berpengetahuan baik. Pengetahuan bukanlah sesuatu yang sudah ada dan tersedia, sementara orang lain tinggal menerimanya. Pengetahuan sebagai suatu pembentukan yang terus menerus oleh seseorang yang setiap saat mengalami reorganisasi karena adanya pemahaman-pemahaman baru ((Budiman \& Riyanto, 2013). Tingkat pengetahuan responden setelah diberikan pendidikan kesehatan, mulai mengalami peningkatan dari pengetahuan kurang menjadi pengetahuan baik, hal ini disebabkan karena responden yang memperhatikan materi penyuluhan dapat memahami apa yang telah disampaikan. Memahami merupakan kemampuan seseorang pada suatu pengetahuan untuk memaparkan dan menginterprestasikan apa yang telah dipelajari dengan tepat.

Hasil penelitian ini kembali sejalan dengan penelitian yang dilakukan oleh Siti Santy Sianipar, dkk. dengan judul "Pengaruh Pendidikan Kesehatan Tentang Anemia Pada kehamilan Terhadap Pengetahuan Ibu Hamil Di UPT Puskesmas Bukit Hindu Palangka Raya Tahun 2016" menunjukkan bahwa setelah diberikan pendidikan kesehatan dari 30 responden terdapat sebanyak $12(40 \%)$ responden yang berpengetahuan baik, 18 (60\%) responden berpengetahuan cukup, sementara tidak ada $(0 \%)$ responden yang berpengetahuan kurang. Siti Santy Sianipar, dkk. berasumsi bahwa pengetahuan dapat diperoleh dari media elektronik, lingkungan, penyuluhan menggunakan media seperti flipchart, metode diskusi, dan lain-lain. Penelitian ini juga didukung oleh penelitian sebelumnya yang dilakukan oleh Rismintari S. Si.T, dengan judul "Pengaruh Pendidikan Kesehatan Melalui Metode Ceramah Terhadap Peningkatan Pengetahuan Tentang Anemia Pada ibu Hamil Di Desa Palbapang Kabupaten Bantul, ditemukan nilai $p$ value 0,01<0,05 sehingga dapat disimpulkan bahwa ada pengaruh yang sangat signifikan terkait tingkat pengetahuan ibu hamil tentang anemia sebelum dan 
sesudah diberikan pendidikan kesehatan. Dimana setelah diberikan pendidikan kesehatan, ibu hamil dapat lebih mudah memahami dan menerapkan konsep anemia dalam kehidupan seharihari.

Dari hasil analisis peneliti setelah diberikan pendidikan kesehatan selama \pm 90 menit responden tersebut banyak bertanya terkait tentang anemia sehingga ini menjadi gambaran awal ibu lebih termotivasi untuk mengetahui seputar tentang anemia dan menjaga pola hidup sehat agar terhindar dari anemia. Ini dibuktikan dari jawaban ibu hamil pada kuesioner yang telah dibagikan peneliti setelah diberikan pendidikan kesehatan sudah banyak yang menjawab benar, khususnya pada point tentang definisi anemia dan klasifikasinya. Peneliti juga berpendapat bahwa dengan memberikan pendidikan kesehatan yang disertai dengan media seperti leaflet sebagai pegangan ibu hamil sambil berdiskusi dapat merangsang dan memotivasi ibu hamil untuk meningkatkan pengetahuan tentang anemia. Tentu untuk merealisasikan hal tersebut, diperlukan kerjasama yang baik antara petugas-petugas kesehatan serta kader-kader yang ada di lingkup wilayah kerja untuk menggerakkan dan memotivasi para ibu hamil agar dapat mengikuti setiap penyuluhan kesehatan dengan menghilangkan pola pikir yang kurang baik yang sudah membudaya di kalangan ibu hamil di wilayah kerja Puskesmas Borong Rappoa.

Hasil penelitian ini menunjukan bahwa ada pengaruh pendidikan kesehatan terhadap tingkat pengetahuan tentang anemia pada ibu hamil di wilayah kerja Puskesmas Borong Rappoa. Berdasarkan hasil uji Wilcoxon bernilai $0,000<0,5$ maka dapat disimpulkan bahwa Ho ditolak yang artinya ada perbedaan proporsi sebelum dan sesudah diberikan pendidikan kesehatan. Pendidikan kesehatan adalah mengubah perilaku seseorang atau masyarakat dari perilaku yang tidak sehat menjadi perilaku sehat. Pendidikan kesehatan dalam keperawatan sangat penting dilakukan agar klien status kesehatannnya meningkat, mencegah timbulnya penyakit, Mempertahankan derajat kesehatan, memaksimalkan fungsi dan peran klien selama sakit, serta membantu klien dan keluarga unuk mengatasi masalah kesehatan (Linggardini \& Aprilina, 2016). Hasil pendidikan kesehatan dapat merubah pengetahuan, pemahaman tentang kesehatan, yang akhirnya akan menerapkan tindakantindakan positif yang menguntungkan kesehatan dan menunjukkan bahwa ada korelasi yang positif terhadap pengetahuan (Linggardini \& Aprilina, 2016).

Penelitian ini menggunakan metode ceramah (penyuluhan) dan diskusi (Tanya jawab) antara pemateri dan responden. Pendidikan kesehatan dengan metode ceramah dan diskusi dapat diberikan kepada sasaran dengan latar belakang pendidikan rendah hingga tinggi. 
Penelitian tersebut sejalan lagi dengan penelitian yang dilakukan oleh Siti Santy Sianipar, dkk. yang berjudul "Pengaruh Pendidikan Kesehatan Tentang Anemia Pada Kehamilan Terhadap Pengetahuan Ibu Hamil di UPT. Puskesmas Bukit Hindu Palangka Raya Tahun 2016" dimana penelitian ini menggunakan uji wilcoxson dan didapatkan nilai $p$ value 0,000 artinya $<0,05$ yang menujukkan bahwa terdapat perbedaan pengetahuan yang bermakna antara sebelum diberikan pendidikan kesehatan dengan sesudah diberikan pendidikan kesehatan pada ibu hamil. Siti Santy Sianipar, dkk. juga berasumsi bahwa media dan strategi yang tepat memang penting untuk meningkatkan pengetahuan ibu hamil (Sianipar, Aziz, \& Prilia, 2016).

Dari hasil analisis peneliti terkait dengan hasil penelitian yang didapatkan bahwa sebelum dilakukan pendidikan kesehatan tentang pengetahuan mengenai anemia terlihat responden lebih banyak kategori kurang karena ibu hamil tersebut belum pernah terpapar informasi sebelumnya. Sedangkan setelah diberikan pendidikan kesehatan terlihat bahwa terdapat peningkatan pengetahuan tentang anemia dikarenakan ibu hamil tersebut telah terpapar informasi tentang anemia dan ibu hamil pada saat diberikan pendidikan kesehatan, mereka tampak antusias mendengarkan materi yang disampaikan, bertanya seputar anemia yang mereka belum dimengerti, serta mereka terlihat lebih termotivasi untuk lebih rutin memeriksakan kehamilannya dan menjaga pola hidup sehat sekaligus pola makan agar terhindar dari anemia pada kehamilan.

Ini membuktikan dari salah satu tingkatan pengetahuan yang mengatakan bahwa tahu diartikan sebagai mengingat suatu materi yang telah dipelajari sebelumnya, kemudian memahami diartikan sebagai kemampuan untuk menjelaskan secara benar tentang obyek yang diketahui dan dapat menginterpretasikan meteri tersebut secara benar, dan aplikasi diartikan sebagai kemampuan untuk menggunakan materi yang telah dipelajari pada situasi yang sebenarnya.

\section{KESIMPULAN DAN SARAN}

Sebelum diberikan pendidikan kesehatan, sebagian besar responden memiliki tingkat pengetahuan kurang. Setelah diberikan pendidikan kesehatan, sebagian besar responden memiliki tingkat pengetahuan baik. Ada perbedaan proporsi sebelum dan sesudah diberikan pendidikan kesehatan. Bagi petugas kesehatan agar kiranya lebih memperhatikan setiap ibu hamil yang ada di lingkup kerjanya dan lebih sering memberikan penyuluhan kesehatan disetiap kelas ibu hamil. 


\section{DAFTAR PUSTAKA}

Aditianti, Yurista, P., \& Diana, J. E. (2015). Pendampingan Minum Tablet Tambah Darah (TTD) Dapat Meningkatkan Kepatuhan Konsumsi TTD Pada Ibu Hamil Anemia, 38(1). Arikunto, S. (2013). Prosedur Penelitian : Suatu Pendekatan Praktik. Jakarta: Rineka Cipata.

Dahlan, M. S. (2011). Langkah-Langkah Membuat Proposal Penelitian Bidang Kedokteran dan Kesehatan. Jakarta: Sagung Seto.

Fathonah, S. (2016). Gizi dan Kesehatan Untuk Ibu Hamil. Jakarta: Erlangga.

Fitri, Y. P., Briawan, D., Tanziha, I., \& Amalia, L. (2015). Kepatuhan Konsumsi Suplemen Besi dan Pengaruhnya Terhadap Kejadian Anemia Pada Ibu Hamil di Kota Tangerang, 10(November), 171-178.

Icesmi, S., \& Sudarti. (2014). Patologi Kehamilan, Persalinan, Nifas dan Neonatus Resiko Tinggi. Yogyakarta: Nuha Medika.

Iswanto, B., Ichsan, B., \& Ermawati, S. (2012). Hubungan Pengetahuan Ibu Hamil Tentang Anemia Defisiensi Besi Dengan Kepatuhan Mengkonsumsi Tablet Besi di Puskesmas Karangdowo, Klaten, 5(2), 110-118.

Jannah, N. (2012). Buku Ajar Asuhan Kebidanan Kehamilan. Yogyakarta: Andi Offse.

Komalasari, R. (2010). Buku Saku Kebidanan. Jakarta: EGC.

Kristanto, V. H. (2018). Metodologi Penelitian: Pedoman Penulisan Karya Tulis Ilmiah. Yogyakarta: CV Budi Utama.

Kristiyanasari, W. (2010). Gizi Ibu Hamil. Yogyakarta: Nuha Medika.

Lapau, B. (2013). Metode Penelitian Kesehatan : Metode Ilmiah Penulisan Skripsi, Tesis, dan Disertasi (2nd ed.). Jakarta: Yayasan Pustaka Obor Indonesia.

Mariza, A. (2016). Hubungan Pendidikan Dan Sosial Ekonomi Dengan Kejadian Anemia Pada Ibu Hamil DI BPS T Yuhan Way Halim Bandar Lampung Tahun, 10 (1), 5-8.

Martono, N. (2010). Metode Penelitian Kuantitatif: Analisa Isi dan Analisis Data sekunder. Jakarta: Raja Grafindo Persada.

Maulana, M. (2010). Panduan Lengkap Kehamilan : Memahami Kesehatan Reproduksi, Cara Menghadapi Kehamilan, dan Kiat Mengasuh Anak. Jogjakarta: Kata Hati.

Megasari, M., Triana, A., Andriyani, R., Ardhiyanti, Y., \& Damayanti, I. P. (2015). Panduan Belajar Asuhan Kebidanan. Yogyakarta: CV Budi Utama.

Muaris, H. (2012). Hidangan Sehat Favorit Ibu Hamil Kehamilan Triwulan Ketiga. Jakarta: PT Gramedia Pustaka Utama.

Mubarak, W. I. (2012). Promosi Kesehatan Untuk Kebidanan. Jakarta: Salemba Medika. 
Noverstiti, E. (2012). Faktor-Faktor Yang Berhubungan Dengan Kejadian Anemia Pada Ibu Hamil Trimester III Di Wilayah Kerja Puskesmas Air Dingin Kota Padang.

Nugroho, T. (2012). Patologi Kebidanan. Yogyakarta: Nuha Medika.

Nurhidayati, R. D. (2013). Analisis Faktor Penyebab Terjadinya Anemia Pada Ibu Hamil Di Wilayah Kerja Puskesmas Tawangsari Kabupaten Sukoharjo.

Oktavia, N. (2015). Sistematika Penulisan Karya Ilmiah. Yogyakarta: Deepublish.

Proverawati, A. (2017). Anemia dan Anemia Kehamilan. Bantul: Nuha Medika.

Purbadewi, L., \& Ulvie, Y. N. S. (2013). Hubungan Tingkat Pengetahuan Tentang Anemia Dengan Kejadian Anemia Pada Ibu Hamil, 2(April), 31-39.

Rismintari. (2015). Pengaruh Pendidikan Kesehatan Melalui Metode Ceramah Terhadap Peningkatan Pengetahuan Tentang Anemia Pada Ibu Hamil Di Desa Palbapang Kecamatan Bantul Kabupaten Bantul.

Setiadi. (2013). Konsep dan Praktek Penulisan Riset Keperawatan. Yogyakarta.

Setyawati, W. A. V., \& Hartini, E. (2018). Buku Ajar Dasar Ilmu Gizi Kesehatan Masyarakat. Yogyakarta: CV Budi Utama.

Shridevi. (2018). Study of prevalence of anemia among pregnant women attending antenatal checkup in a rural teaching hospital in Telangana , India, 7 (7), 2612-2616.

Sianipar, S. S., Aziz, Z. A., \& Prilia, E. (2016). Pengaruh Pendidikan Kesehatan Tentang Anemia Pada Kehamilan Terhadap Pengetahuan Ibu Hamil Di UPT Puskesmas Bukit Hindu Palangka Raya, 7 (1), 266-271.

Simbolon, D., Jumiyati, \& Rahmadi, A. (2018). Pencegahan dan Penanggulangan Kurang Energi Kronik (KEK) dan Anemia Pada Ibu Hamil. Yogyakarta: CV Budi Utama.

Siombo, M. R. (2010). Hukum Perikanan Nasional dan Internasional. Jakarta: PT Gramedia Pustaka Utama.

Soetanto, H., Aulanni'am, Guritno, B., \& Suharto, B. (2013). Model Pendidikan Karakter. malang: Tim UB Press.

Solang, S. D., Losu, N., \& Tando, N. M. (2016). Promosi Kesehatan. Bogor: Penerbit In Media.

Sugiyono. (2018). Metode Penelitian Kuantitatif, Kualitatif, dan R\&D. Bandung: CV Alfabeta.

Sujarweni, V. W. (2014). Metodologi Penelitian Keperawatan. Yogyakarta: Gava Media. Susilo, R. (2015). Pendidikan Kesehatan Dalam Keperawatan. Yogyakarta: Nuha Medika. Swarjana, I. K. (2015). Metodologi Penelitian Kesehatan. Yogyakarta: CV Andi Offset. 
Timotius, K. H. (2017). Pengantar Metodologi Penelitian. Yogyakarta: CV Andi Offset.

Tuyu, S. O. (2013). Hubungan Perilaku Mengkonsumsi Tablet Fe Dengan Kejadian Anemia Pada Ibu Hamil Di Puskesmas Amurang Kecamatan Ambosian Kabupaten Minahasa Selatan, 5 (1), 45-49.

Vivian. (2011). Asuhan Neonatus Bayi dan Balita. Jakarta: Salemba Medika.

Wawan, A., \& Dewi, M. (2011). Teori \& Pengukuran Pengetahuan, Sikap, Dan Perilaku Manusia. Yogyakarta: Nuha Medika.

Zainal, V. R., Kamal, H., \& Muhammad, N. (2014). The Economics Of Education. Jakarta: PT Gramedia Pustaka Utama. 